\title{
Applying Linear Programming in Employee Scheduling Problem during Off-Season: A Case Study
}

\author{
Dr. Manjeet Kharub ${ }^{1}$ and Dr. Gaurav Sharma ${ }^{2}$ \\ ${ }^{1}$ Asst. Professor, CVR College of Engineering/Mechanical Engg. Department, Hyderabad, India \\ Email: manjeetkharub@gmail.com \\ ${ }^{2}$ Asst. Professor, CVR College of Engineering/ECE Department, Hyderabad, India \\ Email: ergaurav209@yahoo.co.in
}

\begin{abstract}
To improve competitive positioning, the effective utilisation of resources has become a favourable consideration for small and medium scale enterprises (SMEs). Among others, the scheduling of staff in SMEs has been regarded as a common problem. So, the present work is an attempt to solve this problem, particularly during the low production days. The study aim is achieved in steps. In the first step, the associated query is transformed into the linear programming problem, and in the second step, the application of MATLAB software is utilized to solve the problem. As a case study, the issue of scheduling for 8-hour shift is discussed. Study results are found in favour of both workers and employees. The study's assumptions may treat as its limitations.
\end{abstract}

Index Terms: Scheduling, Linear Programming, Optimization.

\section{INTRODUCTION}

The increasing global pressure is forcing manufacturing industry to optimise their operation, training and schedules. Optimum production planning has become critically important to sustain in a highly competitive marketplace. In the field of industrial engineering, numerous researchers and practitioners have formulated many methods for scheduling, purchasing, capacity planning and other production activities. Still, in many organisations, the employee's scheduling is a challenging job. Which operator does performing what kind of job? And, when? The solution to these problems must meet certain restrictions concerning demand conditions. These are job experiences, specification, legal or contractual duties, employees' favourites, among others. The solution to these constraints (number of breaks \& their placement, total duration, shift timing \& length) becomes difficult and time-consuming if it is done manually $[1,2]$. Effective scheduling makes decency at the workplace and creates harmony among workers. The modeling of scheduling has broad application in the service and manufacturing sector [3]. Owing to the small number of employees, in general, the scheduling in manufacturing SMEs is not a difficult task, but it becomes complex during off days [4]. The weak scheduling can be a massive barrier to teamwork that can severely affect the worker's output [5]. According to Becker et al. [6] in scheduling the tasks that need to be considered are employee's sequencing, shifting, grouping, timing and so on. Generally, constraints are categorized as (i) hard and (ii) soft constraints. The first category is also termed as mandatory constraints that must be satisfied in order to achieve possible scheduling. The second category is also desirable but has a scope of alteration, therefore can be damaged.

Linear programming (LP) is a mathematical system employed to determine the genuine potential solution in distributing limited assets to achieve the most significant benefit [7]. In particular, LP is a means to deliver the optimal solution for a linear objective function, subjected to linear constraints. Here the term 'programming' has nothing to do with a computer program. It is all related to planning. Planning for optimum solutions and planning for optimum use of available resources and so on. In the current highly competitive marketplace SMEs are in search of increasing benefits with reducing costs and limited utilisation of available resources $[8,9]$. In the present study, an effort has been made to optimise the required number of workers and to assure the worker's availability all the time. The rest of the paper is organized as the following section presents a literature review - sections 3 and 4 present case study design and study results, respectively. Finally, section 5 conclude the results and recommendations for SMEs.

\section{Literature REVIEW}

Dantzig [10] has been considered as founding "father" of linear programming techniques. In world war II, Dantzig was involved in strategy making particularly in the area of transportation and assignment. In 1947 he developed the Simplex method of Linear programming model to solve underlying problems in transportation. The application of this technique was recognised in business organisations after the Second World War, and since then they are continuously being used in various fields. In 1949, Koopmans [11] further developed LP theory. Kuhn and Tucker [12] were the first to check its application in large scale in the scheduling of iron, steel production and paper industries. Practitioners were successful due to its application to different organistional setup.

With its application in different organisational setup practitioners were successful in minimising transport cost.

Kantorovich pointed out that LP can be used to improve economic planning [13]. He used LP on the Russian economy as a whole and established a connection between resource allocation and pricing system. Assar extended the work of Kantorovich and established the connection among a different combination of input and output factors, followed by Cooper who found its application in petroleum refineries. 
Dantzig [14], provided that Nueman worked on the theory of game and the application of LP in it. Further, the Bell Laboratory Mathematician devised an entirely new method to speed up the routine handling of problems by business. The method made it possible to undertake problems that can be used to include a mixture of business and government applications. The earlier trend continued and advanced with changing the degree of knowledge, and the application of LP techniques has reached to daily life situations.

In the year 2004, Ernst et al. [1] presented a scheduling framework model for manual allocation of labour. The framework provided a way to reduce the cost associated with human allocation and production duration. The Genetic algorithm was applied to obtain solutions for the scheduling problem. The decision taken based on study results confirmed that the new optimal solution was profitable. It saved both cost and time.

Similarly, Keitany [3] suggested an alliance methodology solve the employee scheduling problem. The recommended methodology consists of management science and artificial intelligence. It can include the weight to penalise elements (e.g., location \& timing) and gives more reliable results. Fikar \& Hirsch [15] attempted to investigate shift order for the nurse scheduling problem (NSP). The study used LP application to optimise the balance of schedule considering all the constraints. The optimisation result assured the effectiveness of time and effort with a balanced workload.

Hiermann et al. [16] employed a two-stage methodology to solve the nurse scheduling problem. In the first stage, only sequence conditions were analysed to build quality sequences while in the second stage roster constraints were also considered. The comprehensively structured literate on scheduling is well presented in Jorne et al. [17]. In their study, authors have presented through discussion on scheduling its techniques and their features. Further, the study provided future scope and possible improvements in the field of scheduling. Chen and Wang [18] presented an integrated approach for planning in a Canadian steel production industry.

A LP model was developed to design a production and transportation planning system. In this project, researches used real data available with firm and results were calculated. Planning managers well appreciated final project's report and the proposed suggestions were taken seriously in the formulation of a detailed plan model. Overall the employees' scheduling task is crumbled into several small jobs, and then each job is handled individually or few in a group.

Two types of situations are reported in the literature. First, to allow the days off for each employee during the whole training period and the second one is to adjust to the shift of each working day during the training period. These two situations are usually described in the literature, namely, days-off and shift scheduling problems, respectively. When tackled together they are called tour scheduling problem. The tour scheduling problems are commonly observed it industries which operates 24 hours a day and 365 days a year. Further, the tour schedule has been classified into two groups cyclic and non-cyclic depending upon whether all employees have the same or different scheduling.

\section{APPLiCATION OF LP IN A MANUFACTURING FIRM}

The ultimate aim of a firm is to maximise profits or minimise costs incurred to make a product. LP is concerned with decision making at various stages in a production facility and helps in achieving the above-said aim. According to Jorne et al., [17], a typical manufacturing firm has to make three decisions frequently:

- Technical decision: to finalised the method of production.

- Quantity decision: to decide the number of goods to be produced.

- Marketing decision: to forecast sales and growth behaviour.

Technical decisions at the production floor may involve the optimum use of available resources (man, machine and material) with best suitable combination aiming to minimise costs. LP has an essential application in aggregate planning; it also shows how multi-period planning problems can be approached quantitatively. The total plan involves developing a preliminary schedule for overall operations of a firm. In small scale manufacturing industries it is useful in preparing capacity planning for intermediate range.

\section{Case Study Design}

\section{A. Need to study}

The present study is an attempt to optimise the worker's scheduling for manufacturing SMEs operating in the Northern part of India. The company has a packed schedule during the peak production season. However, during 'off' season it has some free slot, which it wants to utilise for employee training. Recently, the company established two automatic centres in sheet metal section. The objective was to utilise off-season time in imparting training on these newly initialled work centres.

\section{B. Problem definition}

Before packaging the product has to go through six shops:

(i) Sheet metal: to cut the raw material into required size with the help of press tools;

(ii) Forging shop: heating and hammering to required shape;

(iii) Machining section: streaming of an extra part after forging (removing scaling);

(iv) Grinding section: to impart surface finish;

(v) Assembling: joining into the final part;

(vi) Electroplating: nickel coating.

Usually, a shift lasts for eight hours, but sometimes workers have to work overtime. During the training days, top management desired that workers should work at least the first 6 hours in their respective shops and then last 2 hours should be utilised for training purpose. The shop-wise requirement of workers during training days is presented in Table 1.

\section{LP problem formulation}

LP often uses an algorithm. An algorithm is a limited set of following directions that drive to an expected objective 
from a given initial situation and that are applied to resolve a problem. A common LP problem requires:

(i) Objective function [criterion to optimise, i.e., profit, costs, return on investment etc.]

(ii) Decision variable [unknown variable to be computed, i.e., input and output.]

(iii) constrained (limited resources); and

(iv) parameters (mathematical statements).

At the production floor generally, its objective is to find the answer to 'how to use available resources optimally. In general, LP algorithms include various iteration steps to accomplish a task. Results are then optimised based on some constraints. The constraints often present the availability of feasible options and lead towards a mathematical model.

\section{In this study, this part was accomplished in four steps:}

Step 1. It was assumed that all works are multitasked, i.e., can perform satisfactory work in any of the shops.

Step 2. Define decision variables, i.e., $V_{1}, V_{2}, V_{3}, V_{5}, V_{6}, V_{7}$ $\& V_{8}$ be the number of workers in the respective shift, i.e., 1 to 8 .

Step 3. Define objective function: Minimize $Z=V_{1}+V_{2}+$ $\mathrm{V}_{3}+\mathrm{V}_{5}+\mathrm{V}_{6}+\mathrm{V}_{7}+\mathrm{V}_{8}$

Step 4. Setting constrained for objective function to be optimize: $\quad \mathrm{V}_{1}+\mathrm{V}_{2} \geq 10 ; \quad \mathrm{V}_{2}+\mathrm{V}_{3} \geq 20 ; \quad \mathrm{V}_{3}+\mathrm{V}_{4} \geq 22 ;$ $\mathrm{V}_{4}+\mathrm{V}_{5} \geq 18 ; \quad \mathrm{V}_{5}+\mathrm{V}_{6} \geq 15 ; \quad \mathrm{V}_{6}+\mathrm{V}_{7} \geq 9 ; \quad \mathrm{V}_{7}+\mathrm{V}_{8} \geq 12 ;$ $\mathrm{V}_{8}+\mathrm{V}_{1} \geq 10 ; \mathrm{V}_{1}, \mathrm{~V}_{2}, \mathrm{~V}_{3}, \mathrm{~V}_{4}, \mathrm{~V}_{5}, \mathrm{~V}_{6}, \mathrm{~V}_{7}, \mathrm{~V}_{8} \geq 0$.

Note: $Z$ represents objective function (i.e., the minimum number of work jointly needed at the beginning of period 1 , 2, 3, 4, 5, 6, 7\& eight respectively).

The worker's requirement in different shops at a various interval of time was calculated and given in Table 1. Table 1 shows a 24:00 hours scheduling where the interval between 8:00 to 11:00 we need a total of 10 workers i.e., 2 in each SM, F, M, A and 1 each in G and E. The maximum worker strength need during 14:00 to 17:00 and minimum during 23:00 to 2:00. All workers are multi-skilled and are willing to join any shop at any period. A worker once entered the industry has to stay for a minimum of 8 hours (6 operations plus 2 hours training). The training hours needs to be scheduled at the end of the shift (last two hours).

D. Analysis and results

The MATLAB software inbuilt function was used to solve the above formulated LPP problems.

Solver: fmincon- constrained nor linear minimisation

Algorithm: Active set

Derivatives: Approximated by the solver

Max iterations: Use default 400

Max function evaluations: Use default*100 number of variables

Function tolerance: 1e-06.

E Results and discussion

Table II depicts the complete schedule during the training period, and Table III answers the question:

Q1. Which worker need to go where?

Q2. Who will come to a particular shop for a particular period?
For instance, as per the requirement, ten workers were needed during the period of 8 to 11 , for that, worker number $1,2,3,57,4,58,59,5,6$ and 7 need to be presented. Worker number $1 \& 2$ needed to go to sheet metal shop, 3 \& 7 were allotted to forging shop, 4 and 58 were assigned machining, only one person, i.e., 59 went to ground, and 5 \& 6 sent to the assembly line, and the worker number 7 remained in electroplating shop. Likewise, table III present the exact number of workers and their duties concerning each shop. Further, the aggregate results of the study showed that:

i. $\quad$ The minimum objective function value is 59 ;

ii. The maximum number of worker required in shift 3 ;

iii. The minimum workers required in shift 6 ;

iv. Worked number 41 and 42 were free during the period from 23:00 to 2:00 were not required in production and could be engaged in other activities (depend upon management decision).

\section{F. Suggested scheduling of workers}

With the help of colour coding suggested scheduling details of workers for training period is prepared and presented in Table 2 .

\section{CONCLUSIONS}

Employees scheduling is, time and cost consuming task. It describes the central administration matters for any organisation, either from manufacture sectors or service sectors. The paper presents a case study of a scheduling problem in manufacturing SME. The chief objective is to find the minimum number of workers who can manage the need of the organisation. An effort has been made to define the constraint satisfaction system regarding shift and worker demands. Based on the study results it can be concluded that the optimum number of workers is 59. Shift 2 needs the maximum number of workers while shift 8 requires a minimum workforce. The critical finding is that two workers (W47 and W 48) are engaged only for 5 hours only rest of the three hours these workers can be utilized, as per the need of the company.

The case study presented in this paper gives the ability to define the number of minimum and maximum employees needed during off time. The manager would also be able to know which worker is free and for how much time so that that appropriate work can be assigned to them during offseason. The worker would get to know where they need to go and for what period. Employees are inhomogeneous concerning their performance, skills levels and status attributes. It limits the scheduling freedom (assigning job). The training period is considered as a critical time to learn new skills; hence the frequent change of job within the different department will provide a sense of responsibility towards obtaining multi-skills. It can be taken as a future work to solve these kind of problems in scheduling context. 
TABLE I.

SIFT WISE WORKER DEMAND

\begin{tabular}{|c|c|c|c|c|c|c|c|c|}
\hline \multirow[t]{2}{*}{ Shift } & \multirow{2}{*}{$\begin{array}{r}\text { Timing } \\
\text { hours/day) }\end{array}$} & \multicolumn{7}{|c|}{ Shopwise minimum requirements } \\
\hline & & $\begin{array}{l}\text { Sheet metal } \\
(\mathrm{SM})\end{array}$ & Forging $(\mathrm{F})$ & $\begin{array}{l}\text { Machining } \\
\text { (M) }\end{array}$ & $\begin{array}{c}\text { Grinding } \\
(\mathrm{G})\end{array}$ & $\begin{array}{l}\text { Assembling } \\
\text { (A) }\end{array}$ & $\begin{array}{c}\text { Electroplating } \\
\text { (E) }\end{array}$ & Total \\
\hline 1 & $8: 00-11: 00$ & 2 & 2 & 2 & 1 & 2 & 1 & 10 \\
\hline 2 & 11:00-14:00 & 3 & 4 & 4 & 3 & 3 & 3 & 20 \\
\hline 3 & $14: 00-17: 00$ & 4 & 4 & 4 & 3 & 4 & 3 & 22 \\
\hline 4 & $17: 00-20: 00$ & 4 & 3 & 4 & 2 & 3 & 2 & 18 \\
\hline 5 & $20: 00-23: 00$ & 2 & 2 & 3 & 2 & 3 & 3 & 15 \\
\hline 6 & $23: 00-2: 00$ & 2 & 2 & 2 & 1 & 1 & 1 & 9 \\
\hline 7 & $2: 00-5: 00$ & 3 & 2 & 2 & 1 & 2 & 2 & 12 \\
\hline 8 & $5: 00-8: 00$ & 2 & 2 & 2 & 2 & 1 & 1 & 10 \\
\hline
\end{tabular}

TABLE II.

SugGESTED SHIFT SCHEdule

\begin{tabular}{|c|c|c|c|c|c|c|c|c|c|c|c|c|c|c|c|c|}
\hline \multirow[t]{2}{*}{ Worker } & \multicolumn{16}{|c|}{ Shift timing } \\
\hline & \begin{tabular}{|l|}
$8: 00-$ \\
$10: 00$ \\
\end{tabular} & $\begin{array}{l}10: 00- \\
11: 00 \\
\end{array}$ & \begin{tabular}{|l|}
$11: 00-$ \\
$13: 00$ \\
\end{tabular} & $\begin{array}{l}13: 00- \\
14: 00\end{array}$ & \begin{tabular}{|l|}
$14: 00-$ \\
$16: 00$ \\
\end{tabular} & $\begin{array}{l}16: 00- \\
17: 00 \\
\end{array}$ & $\begin{array}{l}17: 00- \\
19: 00 \\
\end{array}$ & $\begin{array}{l}19: 00- \\
20: 00\end{array}$ & $20: 00-22: 00$ & $\begin{array}{l}22: 00- \\
23: 00\end{array}$ & \begin{tabular}{|l|l}
$23: 00-$ & 1 \\
$1: 00$ & 2 \\
\end{tabular} & \begin{tabular}{|l|}
$1: 00-$ \\
$2: 00$ \\
\end{tabular} & 2:00-4:00 & \begin{tabular}{|l|}
$4: 00-$ \\
5:00 \\
\end{tabular} & \begin{tabular}{|l}
$5: 00-$ \\
700 \\
\end{tabular} & \begin{tabular}{|l|}
$7: 00-$ \\
$8: 00$ \\
\end{tabular} \\
\hline W1 & \multicolumn{4}{|c|}{ Sheet metal } & Training & & & & & & & & & & & \\
\hline W2 & \multicolumn{4}{|c|}{ Sheet metal } & Training & & & & & & & & & & & \\
\hline W3 & \multirow{2}{*}{\multicolumn{4}{|c|}{\begin{tabular}{|l|} 
Forging \\
Machining \\
\end{tabular}}} & Training & & & & & & & & & & & \\
\hline W4 & & & & & Training & & & & & & & & & & & \\
\hline W5 & \multicolumn{4}{|c|}{ Assembly } & Training & & & & & & & & & & & \\
\hline W6 & \multicolumn{4}{|c|}{ Assembly } & Training & & & & & & & & & & & \\
\hline W7 & \multicolumn{4}{|c|}{ Electroplating } & Training & & & & & & & & & & & \\
\hline W8 & & & \multicolumn{4}{|c|}{ Sheet metal } & Training & & & & & & & & & \\
\hline W9 & & & \multirow{2}{*}{\multicolumn{4}{|c|}{\begin{tabular}{|l|} 
Forging \\
Forging \\
\end{tabular}}} & Training & & & & & & & & & \\
\hline W10 & & & & & & & Training & & & & & & & & & \\
\hline W11 & & & \multicolumn{4}{|l|}{ Forging } & Training & & & & & & & & & \\
\hline W12 & & & \multicolumn{4}{|c|}{ Machining } & Training & & & & & & & & & \\
\hline W13 & & & \multicolumn{4}{|c|}{\begin{tabular}{|l|} 
Machining \\
Machining
\end{tabular}} & Training & & & & & & & & & \\
\hline W14 & & & \multirow{2}{*}{\multicolumn{4}{|c|}{\begin{tabular}{|l} 
Machining \\
Grinding
\end{tabular}}} & Training & & & & & & & & & \\
\hline W15 & & & & & & & Training & & & & & & & & & \\
\hline W16 & & & Grindin & & & & Training & & & & & & & & & \\
\hline W17 & & & Grindin & & & & Training & & & & & & & & & \\
\hline W18 & & & Assemb & & & & Training & & & & & & & & & \\
\hline W19 & & & Electro & lating & & & Training & & & & & & & & & \\
\hline W20 & & & Electro & lating & & & Training & & & & & & & & & \\
\hline W21 & & & & & Sheet $\mathrm{mc}$ & & & & Training & & & & & & & \\
\hline W22 & & & & & Sheet $\mathrm{mc}$ & & & & Training & & & & & & & \\
\hline W23 & & & & & Sheet $\mathrm{mc}$ & & & & Training & & & & & & & \\
\hline W24 & & & & & Forging & & & & Training & & & & & & & \\
\hline W25 & & & & & Machini & & & & Training & & & & & & & \\
\hline W26 & & & & & Assembl & & & & Training & & & & & & & \\
\hline W27 & & & & & Assembl & & & & Training & & & & & & & \\
\hline W28 & & & & & Assembl & & & & Training & & & & & & & \\
\hline W29 & & & & & Electrop & lating & & & Training & & & & & & & \\
\hline W30 & & & & & & & Sheet me & & & & Training & & & & & \\
\hline W31 & & & & & & & Forging & & & & Training & & & & & \\
\hline W32 & & & & & & & Forging & & & & Training & & & & & \\
\hline W33 & & & & & & & Machinin & & & & Training & & & & & \\
\hline W34 & & & & & & & Machinin & & & & Training & & & & & \\
\hline W35 & & & & & & & Machinin & & & & Training & & & & & \\
\hline W36 & & & & & & & Grinding & & & & Training & & & & & \\
\hline W37 & & & & & & & Grinding & & & & Training & & & & & \\
\hline W38 & & & & & & & Electropl & lating & & & Training & & & & & \\
\hline W39 & & & & & & & & & Sheet metal & & & & Training & & & \\
\hline W40 & & & & & & & & & Assembly & & & & Training & & & \\
\hline \begin{tabular}{|l|} 
W41 \\
\end{tabular} & & & & & & & & & Assembly & & & & Training & & & \\
\hline W42 & & & & & & & & & Assembly & & Free sl & slot & Training & & & \\
\hline W43 & & & & & & & & & Electroplating & & & & Training & & & \\
\hline W44 & & & & & & & & & Electroplating & & Machining & & Training & & & \\
\hline W45 & & & & & & & & & & & Forging & & & & Training & \\
\hline W46 & & & & & & & & & & & Machining & & & & Training & \\
\hline \begin{tabular}{|l|} 
W47 \\
\end{tabular} & & & & & & & & & & & Grinding & & & & Training & \\
\hline W48 & & & & & & & & & & & Forging & & Electroplat & ting & Training & \\
\hline W49 & & & & & & & & & & & Sheet meta & & & & Training & \\
\hline W50 & Training & & & & & & & & & & & & & Sheet & netal & \\
\hline W51 & Training & & & & & & & & & & & & & Sheet $\mathrm{n}$ & netal & \\
\hline
\end{tabular}




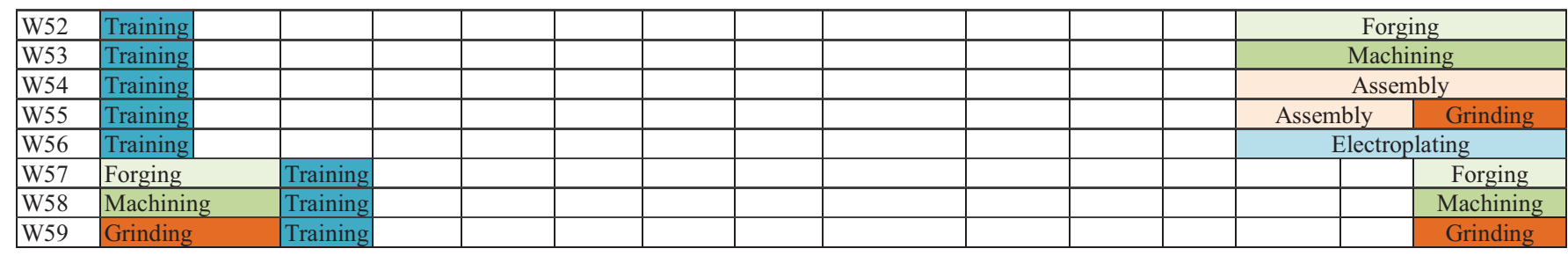

TABLE III

WORKS ALLOTMENT TO ALL DEPARTMENT DURING TRAINING PERIOD

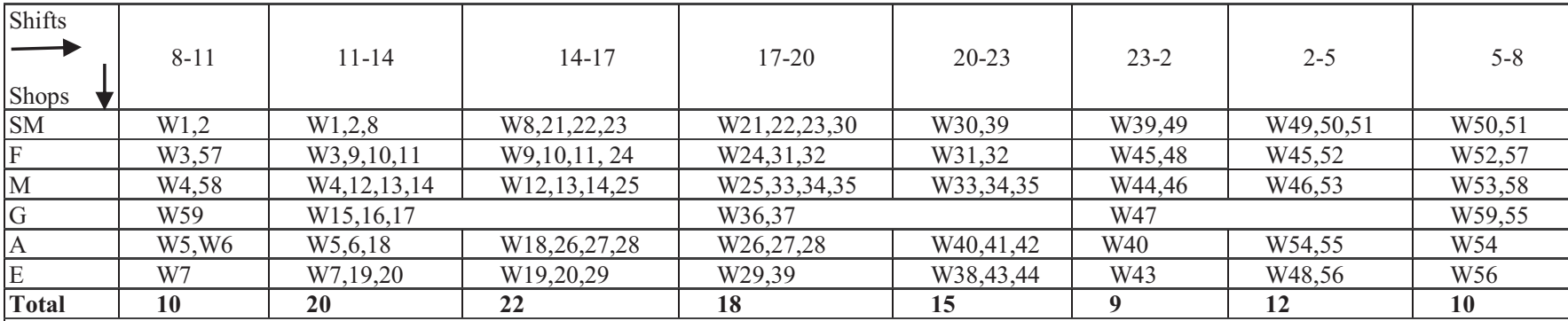

Where: SM= Sheet metal; F=Forging; $\mathrm{M}=$ Machining; $\mathrm{G}=$ Grinding; $\mathrm{A}=$ Assembly; $\mathrm{E}=$ Electroplating; W=Worker, and the number represent a particular worker.

\section{REFERENCES}

[1] Ernst, A. T., Jiang, H., Krishnamoorthy, M., \& Sier, D., "Staff scheduling and rostering: A review of applications, methods and models." European journal of operational research, vol. 153, no. 1, pp. 3-27, Feb. 2014.

[2] Glock, C. H., Grosse, E. H., Elbert, R. M., \& Franzke, T., "Maverick picking: the impact of modifications in work schedules on manual order picking processes." International Journal of Production Research, vol. 55, no. 21, pp. 63446360, Nov. 2017.

[3] Keitany, B. J., "Perceived relationship between employee welfare programs and employee performance at Kenya Pipeline Company." Unpublished MBA Project, University of Nairobi, March 2014.

[4] Harper, C., "Organizations: Structures, processes and outcomes. Routledge. Aug. 2015.

[5] Kerzner, H., \& Kerzner, H. R. "Project management: a systems approach to planning, scheduling, and controlling”, John Wiley \& Sons, April 3, 2017.

[6] Becker, T., Steenweg, P. M., \& Werners, B., "Cyclic shift scheduling with on-call duties for emergency medical services", Health care management science, pp. 1-15, July 2018.

[7] Dantzig, G., "Linear programming and extensions. Princeton university press," Aug. 2016

[8] Kharub, M., Limon, S., \& Sharma, R. K., "The application of quality tools in effective implementation of HACCP: An empirical study of food and pharmaceutical industries", International Journal of Quality \& Reliability Management, vol. 35, no. 9, pp. 1920-1940, Oct. 2018.

[9] Kharub, M., \& Sharma, R. K., "Framework to assess competitive positioning in manufacturing industries," International Journal of Business Excellence, vo. 12, no. 2, pp. 139-174, Feb. 2017.

[10] Dantzig, G.B. (1963) "Linear Programming and Extensions (Princeton University Press", Princeton, New Jersey.

[11] Koopmans, T.C., "Optimum utilization of the transportation system. Econometrica", Journal of the Econometric Society, pp.136-146, .July 1949.
[12] Kuhn, H. W., \& Tucker, A. W. (Eds.) "Contributions to the Theory of Games", Princeton University Press, vol. 1, no. 2, pp. 244-256, 1950.

[13] Kantorovich, L.V. "Mathematical Methods in the Organization and Planning of Production" Translated in Management Science', vol. 6 no.1 pp. 336-422, August 1939.

[14]Dantzig, G., "Linear programming and extensions", Princeton university press. August 2016.

[15] Fikar, C., \& Hirsch, P., "Home health care routing and scheduling: A review. Computers \& Operations Research", vol. 77, pp. 86-95, Jan. 2017.

[16] Hiermann, G., Prandtstetter, M., Rendl, A., Puchinger, J., \& Raidl, G. R., "Metaheuristics for solving a multimodal homehealthcare scheduling problem", Central European Journal of Operations Research, vol. 23, no. 1, pp. 89-113. March 2015.

[17] Jorne, V den B, Jeroen B, Philippe De B, Erik D., \& Liesje De B.,"Personnel scheduling: A literature review," Hub Research Papers 2012/43, Economics \& Management, 1-40. Dec. 2012.

[18] Chen, M.. \& Wang, W., "A linear programming model for integrated steel production and distribution planning", International Journal of Operations \& Production Management, vol. 17, no. 6, pp. 592-610. June 1997. 